\title{
Evaluation of personal exposure to monoaromatic hydrocarbons
}

\author{
Pei-Ling Leung, Roy M Harrison
}

\begin{abstract}
Objectives-To evaluate the personal exposure of members of the general public to atmospheric benzene, toluene, and the xylenes, excluding exposure from active smoking.

Method-50 volunteers were equipped with active air samplers for direct measurement of personal exposure to monoaromatic hydrocarbons (MAH) and an activity diary was completed during each sampling period. Exposures were also estimated indirectly by combining activity data with independent measurements of hydrocarbon concentrations in several microenvironments.
\end{abstract}

Results-Personal exposures were generally well in excess of those which would be inferred from outdoor measurements from an urban background monitoring station. A wide range of sources contribute to exposure, with indoor and in car concentrations generally exceeding those measured at background outdoor locations. Environments contaminated with tobacco smoke were among those exhibiting the highest concentrations. Personal exposures determined indirectly from activity diaries/microenvironment measurements were well correlated with those determined directly with personal samplers. Personal 12 hour daytime exposures to benzene ranged from $0.23-88.6 \mathrm{ppb}$ (mean $3.81 \mathrm{ppb}$ ), with 12 hour night time exposures of 0.61-5.67 ppb (mean 1.94 ppb) compared with an annual average concentration of $1.18 \mathrm{ppb}$ at the nearest suburban fixed site monitoring station. The excess of personal exposure over fixed site concentrations was greater for benzene and toluene than for the xylenes.

Institute of Public and Environmental Health, School of Chemistry, University of Birmingham,

Edgbaston,

Birmingham B15 2TT, UK

P-L Leung

R M Harrison

Correspondence to: Professor Roy M Harrison, Institute of Public and Environmental Health, School of Chemistry, University of Birmingham, Edgbaston, Birmingham B15 2TT, United Kingdom.

Accepted 4 November 1997
Conclusion-A wide range of sources contribute to personal exposures to monoaromatic hydrocarbons with exposure duration being as important a determinant of total exposure as concentrations. Exposures generally exceed those estimated from concentrations measured by background fixed point monitors. Microenvironment sampling combined with activity diary information can provide satisfactory estimates of personal exposure to these compounds.

(Occup Environ Med 1998;55:249-257)

Keywords: benzene; personal exposure; aromatic hydrocarbons
At high concentrations benzene, toluene, and the xylenes all have serious adverse effects on human health. At typical ambient concentrations, however, the focus of interest is on benzene because of its known genotoxic carcinogenicity, and in the United Kingdom the Expert Panel on Air Quality Standards ${ }^{1}$ has recommended that benzene concentrations should not exceed $5 \mathrm{ppb}$ as a running annual average, with a long term target of $1 \mathrm{ppb}$. In its national air quality strategy, the United Kingdom government has accepted $5 \mathrm{ppb}$ as a specific objective to be met by the year 2005 . Although there is currently little firm evidence of adverse health effects of toluene and the xylenes at typical outdoor ambient concentrations, because of their chemical similarity to benzene, they are often measured and have been included in this study. The World Health Organisation $^{2}$ has recently recommended a guideline for toluene of $260 \mu \mathrm{g} \mathrm{m}^{-3}$ (68 ppb) as a weekly average concentration to protect against developmental neurotoxicity.

The United Kingdom 1991 atmospheric emissions inventory for speciated volatile organic compounds ${ }^{3}$ ascribed the major proportion (97\%) of benzene emissions to motor vehicle exhaust or evaporative losses of fuel during production, distribution, and use. These are major sources also for toluene, $o$-, $m$-, and $p$-xylene $(65 \% ; 60 \% ; 65 \%$, and $65 \%$ respectively) but for these compounds solvents also provide an important contribution $(35 \%$; $40 \% ; 35 \%$, and $35 \%$ respectively). Many developed countries have monitoring networks that measure concentrations of aromatic hydrocarbons in the atmosphere. The United Kingdom has one of the most advanced networks with continuous automated chromatography providing time integrated measurements each hour through day and night. ${ }^{4}$ Such measurements are made at fixed point monitoring stations, which in the United Kingdom are at urban background locations. Although this approach is well suited to evaluating the general pollution climate and for monitoring trends in atmospheric concentrations, earlier research on personal exposures to pollutants has shown that the measurements at such stations may not well represent the exposures of individual members of the general population. Previous studies of personal exposure ${ }^{56}$ have highlighted prominent sources of benzene. Outdoor exposures to benzene are primarily connected with vehicle emissions, including both exhaust and evaporative losses of benzene; toluene and xylene are known to arise from the same sources. Recent studies have shown that in areas of high traffic density 
Table 1 Type and sampling condition of each microenvironment

\begin{tabular}{|c|c|c|}
\hline Microenvironment & Sampling condition & $\begin{array}{l}\text { Observations } \\
\text { (n) }\end{array}$ \\
\hline Railway train & $\begin{array}{l}\text { In train carriage, while travelling around Birmingham, and to and from London and } \\
\text { Cardiff }\end{array}$ & 15 \\
\hline London underground & In underground carriage, travelling on all main underground lines & 15 \\
\hline Pedestrian area & Pedestrianised shopping centres in Surrey and Birmingham & 15 \\
\hline Painted room & $\begin{array}{l}\text { Sampling while rooms were being painted; ventilation conditions were set to the request } \\
\text { of the painter }\end{array}$ & 14 \\
\hline Campus & Roof of the radiation centre (height of $15 \mathrm{~m}$ ) from $8.00 \mathrm{am}$ to $8.00 \mathrm{pm}$ & 13 \\
\hline Smoky bar & $\begin{array}{l}\text { Bar situated at the guild of students; repeated samples between } 7.00 \mathrm{pm}-12.00 \mathrm{pm} \text { over a } \\
\text { week }\end{array}$ & 16 \\
\hline Car park & $\begin{array}{l}\text { First level at the south car park (multi-storey) on campus; repeated samples between } \\
7.00 \mathrm{am}-7.00 \mathrm{pm} \text { over a week }\end{array}$ & 16 \\
\hline City centre & Roof of the repertory theatre, Birmingham (height of $25 \mathrm{~m}$ ) & 10 \\
\hline Living room (daytime) & Selection of non-smoking homes around Birmingham and the south east & 15 \\
\hline Cooking & Evening cooking times only over a period of several days & 12 \\
\hline Roadside & Monitoring alongside most major roads in Birmingham & 44 \\
\hline Driving & In vehicle sampling while driving along major roads in Birmingham & 52 \\
\hline Tunnel & Roadside sampling inside the Queensway tunnel (Birmingham) between $7.00 \mathrm{am}-7.00 \mathrm{pm}$ & 10 \\
\hline Office & Monitoring a variety of offices between $9.00 \mathrm{am}-5.00 \mathrm{pm}$ & 15 \\
\hline Refuelling & Out vehicle exposure while refuelling & 15 \\
\hline
\end{tabular}

concentrations in vehicles are typically manyfold higher than are measured at urban background locations (personal communication). For example, concentrations in vehicles on a busy street in Birmingham, United Kingdom were $18.6 \mathrm{ppb}$ for benzene whereas concurrently measured concentrations at the urban background monitoring station in the same city averaged $0.82 \mathrm{ppb}$. Increased exposures were also measured when refuelling the car and walking along main roads (personal communication). However, the TEAM study in the United States estimated that activities related to motor cars accounted for only about $20 \%$ of the nationwide burden of benzene exposure. ${ }^{5}$ Sources of indoor hydrocarbons are numerous, including building materials, solvents, adhesives, and environmental tobacco smoke. ${ }^{6}$ The TEAM study ${ }^{5}$ found tobacco smoke to be the most prominent source of indoor pollution, with benzene concentrations increasing by up to $50 \%$ compared with homes of non-smokers. However, due to low dilution rates and the amount of time spent indoors, even minor sources - for example, mothballscan contribute considerably to exposure. Such sources include several consumer products which when combined together can account for up to $20 \%$ of the exposure of the total population to benzene. ${ }^{6}$

Estimation of personal exposure can be conducted either directly by attaching personal samplers to people, or indirectly by fixed point monitors in individual microenvironments combined with activity data defining the times spent in each of the microenvironments. A recent study of exposure to lead in Mexico $\mathrm{City}^{8}$ showed an excellent correlation between the two approaches, but little comparative work has been conducted. In this study we have used both approaches to estimate the personal exposure to monoaromatic hydrocarbons (BTX) for four major categories of people (office workers, students, elderly people, and homemakers). We have compared direct personal exposure measurements with indirect estimates from microenvironment monitoring with independent microenvironment data combined with activity diaries kept by the people wearing personal samplers. Our study has included the effects of passive intake of tobacco smoke, but unlike the estimates reported by Wallace for benzene intake, ${ }^{5}$ has explicitly excluded direct intake by tobacco smokers.

\section{Methods}

SAMPLING METHODS

Personal exposures to monoaromatic hydrocarbons were measured by a series of personal sampling (50 volunteers) and microenvironment measurements.

Table 2 Mean (SD) concentrations of MAH in different microenvironments ( $p p b$ )

\begin{tabular}{|c|c|c|c|c|c|c|c|c|c|c|c|c|}
\hline \multirow[b]{2}{*}{ Microenvironment } & \multicolumn{3}{|c|}{ Benzene } & \multicolumn{3}{|c|}{ Toluene } & \multicolumn{3}{|c|}{$p$ and $m$-Xylene } & \multicolumn{3}{|c|}{ o-Xylene } \\
\hline & $\begin{array}{l}\text { Geo } \\
\text { mean }\end{array}$ & $\begin{array}{l}\text { Arith } \\
\text { mean }\end{array}$ & $\begin{array}{l}\text { Arith } \\
S D\end{array}$ & $\begin{array}{l}\text { Geo } \\
\text { mean }\end{array}$ & $\begin{array}{l}\text { Arith } \\
\text { mean }\end{array}$ & $\begin{array}{l}\text { Arith } \\
S D\end{array}$ & $\begin{array}{l}\text { Geo } \\
\text { mean }\end{array}$ & $\begin{array}{l}\text { Arith } \\
\text { mean }\end{array}$ & $\begin{array}{l}\text { Arith } \\
S D\end{array}$ & $\begin{array}{l}\text { Geo } \\
\text { mean }\end{array}$ & $\begin{array}{l}\text { Arith } \\
\text { mean }\end{array}$ & $\begin{array}{l}\text { Arith } \\
S D\end{array}$ \\
\hline Railway train & 3.6 & 4.1 & 2.3 & 2.7 & 4.6 & 4.3 & 1.0 & 1.4 & 1.2 & 1.2 & 1.2 & 1.2 \\
\hline London underground & 3.4 & 3.8 & 1.9 & 5.4 & 10.0 & 8.1 & 1.6 & 1.4 & 1.4 & 0.7 & 0.7 & 0.7 \\
\hline Pedestrian area & 5.6 & 5.7 & 0.9 & 2.7 & 3.1 & 1.5 & 1.0 & 1.0 & 1.4 & 0.1 & 0.1 & 0.2 \\
\hline Painted room & 5.9 & 6.3 & 2.9 & 23.3 & 30.0 & 18.4 & 24.6 & 25.8 & 9.4 & 9.0 & 11.4 & 7.9 \\
\hline Campus & 3.5 & 3.7 & 1.3 & 2.6 & 3.3 & 2.5 & 1.4 & 1.9 & 1.3 & 1.5 & 1.5 & 1.2 \\
\hline Smoky bar & 24.0 & 24.7 & 6.6 & 24.8 & 30.0 & 21.7 & 2.4 & 2.9 & 1.9 & 1.6 & 1.9 & 1.2 \\
\hline Car park & 16.4 & 17.8 & 6.7 & 10.0 & 10.7 & 3.6 & 3.0 & 3.3 & 1.1 & 1.6 & 3.3 & 3.2 \\
\hline City centre & 4.3 & 4.4 & 0.7 & 5.6 & 5.7 & 1.2 & 0.1 & 0.2 & 0.1 & 0.0 & 0.01 & 0.01 \\
\hline Non-smoking house & 3.6 & 3.6 & 0.7 & 5.6 & 5.8 & 1.6 & 2.1 & 2.2 & 0.8 & 0.4 & 0.4 & 0.2 \\
\hline Cooking & 4.4 & 4.6 & 1.5 & 9.7 & 10.0 & 2.7 & 3.2 & 3.3 & 0.7 & 0.6 & 0.7 & 0.2 \\
\hline Tunnel & 29.1 & 30.9 & 10.0 & 73.6 & 75.0 & 15.6 & 22.7 & 23.2 & 5.2 & 5.1 & 5.5 & 2.5 \\
\hline Driving & 8.4 & 12.9 & 10.9 & 10.2 & 31.1 & 54.7 & 1.5 & 2.9 & 3.2 & 0.8 & 2.5 & 1.5 \\
\hline Pavement & 8.1 & 8.6 & 2.9 & 18.5 & 21.1 & 9.8 & 6.5 & 8.4 & 4.9 & 1.6 & 2.5 & 2.7 \\
\hline Refuelling & 59.5 & 59.5 & 48.4 & 131.7 & 131.7 & 133.7 & 5.7 & 5.7 & 2.0 & 2.9 & 2.9 & 2.0 \\
\hline Office & 3.8 & 3.9 & 1.3 & 5.9 & 5.9 & 3.2 & 3.3 & 3.3 & 0.6 & 0.8 & 0.8 & 0.6 \\
\hline
\end{tabular}


Table 3 Concentrations within homes compared with previously reported data ( $p p b$ )

\begin{tabular}{|c|c|c|c|c|c|c|}
\hline Compound & This study & West Germany* & $U S A+$ & Netherlands $\neq$ & Hertfordshire $(U K)$ & Avon \\
\hline Benzene & 4.93 & 3.13 & 5.02 & 1.88 & 3.45 & 2.51 \\
\hline Toluene & 11.89 & 22.32 & Not measured & 9.3 & 7.71 & 13.3 \\
\hline$p$ and $m$-Xylene & 6.07 & 5.30 & 5.99 & $2.30^{\star \star}$ & Not measured & measured \\
\hline$o$-Xylene & 1.15 & 1.16 & 2.07 & & measured & measured \\
\hline
\end{tabular}

${ }^{\star}$ Two week averages; 488 homes in former West Germany. ${ }^{10}$

†24 hour averages; 526 people in New Jersey and California. ${ }^{5}$

$\ddagger$ One week averages; 319 homes in The Netherlands. ${ }^{11}$

$\S$ Measurements in main living rooms; six homes in Hertfordshire. ${ }^{12}$

ๆMeasurements in living rooms; 173 homes in Avon. ${ }^{12}$

${ }^{\star \star}$ Measured as $p / m / o$-xylene.

\section{Sampling location}

Most microenvironments monitored in the independent microenvironment study were based in Birmingham (table 1), a city with a population of about one million. Due to the location of the city and its industrial links, Birmingham has an extensive road network with large sections heavily congested. In contrast, although most of the personal exposure monitoring study was based in Birmingham (28 volunteers returned full 12 hour samples), about one third of all volunteers were located in less urban regions (16 volunteers provided full samples). These included small towns surrounded by countryside and small villages in rural locations. Therefore, roads were typically less congested and ambient air concentrations were lower.

\section{Microenvironment monitoring}

Sampling was performed by drawing air at a rate of $200 \mathrm{ml} \mathrm{min}^{-1}$ through stainless steel sorbent tubes packed with Tenax TA (35-60 mesh) for 30 minutes. For automatic sampling, sorbent tubes were attached to an eight port valve sampler. However, in some microenvironments, sampling through the autosampler was inconvenient. Therefore, a personal pump with an attached sorbent tube (changed every hour) was used. Some short term samples were also collected into evacuated SUMMA canisters (see later), for example during car refuelling. Microenvironments chosen were common areas occupied by the public with either high hydrocarbon concentrations-for example, road tunnel-or long exposure times-for example, the home. Table 1 shows the sampling locations. As most direct personal monitoring experiments were based around Birmingham, nearly all microenvironment measurements were concentrated in this city. However, for prominent environments featured in activity diaries - for example, the home-a section of locations around the United Kingdom was monitored to give a representative range.

Personal exposure monitoring: daytime

After the selection of 50 volunteers (from various backgrounds), personal exposure was determined directly over a series of 12 hour daytime sampling periods. A personal pump was used to draw air through a sorbent tube (attached to the volunteer's lapel) at a rate of $100 \mathrm{ml} \mathrm{min}{ }^{-1}$ for one hour. At the end of each hour sampling period, volunteers were instructed to change the sorbent tube and to fill in a questionnaire stating their activity during the sampling period and a summary of their activities over the one year period. This was repeated throughout the day (0800-2000). Due to the complexity of the sampling, only one 12 hour period per subject was studied and the whole sampling campaign took one year (summer 1995 to summer 1996) to complete.

\section{Personal exposure monitoring: night time}

Night time exposure was monitored from 0800-2000 inside bedrooms. Not all 50 volunteers were monitored due to the intrusive nature of the sampling. Overnight sampling was performed by two methods.

(1) Hourly samples with the eight port sampler were collected throughout the night. However, due to the noise from the equipment, this method was not a viable option for many volunteers.

(2) Twelve hour time integrated samplers were collected by SUMMA canisters. Time integrated samples were taken by evacuating the canister to about 1 mbar. Air was then drawn into the container at a set flow rate throughout the night. After sampling, the canister was then pressurised further to 20 psi with zero nitrogen for subsequent analysis.

Table 4 Personal exposure during night and day compared with annual MAH concentration from the AUN site for urban volunteers $(p p b)$

\begin{tabular}{|c|c|c|c|c|c|c|c|c|c|}
\hline \multirow[b]{2}{*}{ Compound $^{\star}$} & \multicolumn{4}{|c|}{ Day concentrations } & \multicolumn{4}{|c|}{ Night concentrations } & \multirow{2}{*}{$\begin{array}{l}\text { AUN mean } \\
\text { annual } \\
\text { concentrations }\end{array}$} \\
\hline & Mean & Range & $S D$ & $\begin{array}{l}\text { Observationst } \\
\text { (n) }\end{array}$ & Mean & Range & $S D$ & $\begin{array}{l}\text { Observations } \\
\text { (n) }\end{array}$ & \\
\hline Benzene & 4.69 & $0.73-88.58$ & 3.49 & 28 & 3.44 & $0.61-5.67$ & 2.36 & 5 & 1.18 \\
\hline $\begin{array}{l}\text { Toluene } \\
p \text { and }\end{array}$ & 8.43 & $0.95-142.26$ & 5.56 & 28 & 13.98 & $8.89-23.68$ & 6.37 & 5 & 2.49 \\
\hline$m$-Xylene & 1.94 & $0.004-63.64$ & 2.48 & 28 & 5.19 & $1.86-10.12$ & 3.10 & 5 & 1.63 \\
\hline$o$-Xylene & 0.67 & $0.23-18.74$ & 0.75 & 28 & 0.78 & $0.21-1.50$ & 0.55 & 5 & 0.54 \\
\hline
\end{tabular}

*Monoaromatic hydrocarbon.

†Number of daytime volunteers sampled and returning a full 12 samples during the 12 hour personal monitoring experiment. 
Table 5 Personal exposure during night and day for non-urban volunteers ( $p p b$ )

\begin{tabular}{|c|c|c|c|c|c|c|c|c|}
\hline \multirow[b]{2}{*}{ Compound ${ }^{\star}$} & \multicolumn{4}{|c|}{ Day concentrations } & \multicolumn{4}{|c|}{ Night concentrations } \\
\hline & Mean & Range & $S D$ & Observationst (n) & Mean & Range & $S D$ & Observations (n) \\
\hline Benzene & 2.98 & $0.23-16.89$ & 1.73 & 16 & 2.22 & $1.0-4.75$ & 1.45 & 6 \\
\hline Toluene & 6.95 & $0.67-46.22$ & 4.97 & 16 & 3.90 & $0.74-9.58$ & 3.30 & 6 \\
\hline$p$ and $m$-Xylene & 1.65 & $0.11-8.28$ & 1.15 & 16 & 5.36 & $1.37-9.35$ & 5.64 & 6 \\
\hline$o$-Xylene & 0.64 & $0.05-4.40$ & 0.57 & 16 & 0.92 & $0.03-1.7$ & 0.88 & 6 \\
\hline
\end{tabular}

†Number of daytime volunteers sampled and returning a full 12 samples during the 12 hour personal monitoring experiment.

\section{ANALYTICAL METHODS}

Sorbent tube samples

After air sampling, sorbent tubes were analysed for benzene, toluene, and xylene (all three isomers). Samples were placed inside a Perkin Elmer ATD50 thermal desorber. Each tube underwent primary desorption at $250^{\circ} \mathrm{C}$ for 30 minutes. Desorbed compounds were cryofocused in a cold trap held at $-30^{\circ} \mathrm{C}$. After focusing, the trap underwent rapid heating to $250^{\circ} \mathrm{C}$ to volatilise the compounds into a Hewlett Packard 5890 Series II gas chromatograph (GC), equipped with a flame ionisation detector. Due to the low concentrations present in ambient air, the sample was not split at either the thermal desorption or gas chromatography stage of analysis. The gas chromatography and temperature programming conditions were as follows: $100^{\circ} \mathrm{C}$ for 15 minutes, $100-180^{\circ} \mathrm{C}$ at a rate of $5^{\circ} \mathrm{C} \mathrm{min}^{-1}, 180^{\circ} \mathrm{C}$ for 20 minutes, 180 $200^{\circ} \mathrm{C}$ at $5^{\circ} \mathrm{C} \mathrm{min}^{-1}, 200^{\circ} \mathrm{C}$ for 20 minutes; detector and injector temperatures, $250^{\circ} \mathrm{C}$ and $150^{\circ} \mathrm{C}$ respectively. For gas chromatographic separation a GC alumina PLOT column $50 \mathrm{~m}$ $\times 0.53 \mathrm{~mm}, 10 \mu \mathrm{m}$ film thickness (Chrompack UK, Millharbour, London) was used. Identification of chromatographic peaks was by retention times. However, peak assignment was confirmed by analysing air samples with mass spectrometry (Hewlett Packard HP5871A MSD). To compensate for any drifts in retention times and responses, a sorbent tube containing a known concentration of standard sampled from a permeation tube system was analysed after every two sorbent tubes. The precision of sampling and analysis determined by parallel sampling was $\pm 5 \%$.

\section{Grab or time integrated samples (by SUMMA canister)}

SUMMA canister samples were analysed with thermal desorption-gas chromatographymass spectrometry. An adapted purge and trap system (Aerotrap 6000, Ohio, America) was used for cryofocusing hydrocarbons present in air samples. A known volume of sample was introduced into a cold trap (held at $-165^{\circ} \mathrm{C}$ by pressurised liquid nitrogen) for 10 minutes.

Table 6 Comparison of daytime benzene personal exposure concentration ( $p p b)$ with previously published data

\begin{tabular}{|c|c|c|c|c|c|c|c|}
\hline \multirow[b]{2}{*}{ Time } & \multirow[b]{2}{*}{ This study UK } & \multicolumn{6}{|c|}{ Published data from Wallace et al ${ }^{5}$} \\
\hline & & $\mathrm{Nf}$ & $N C$ & $L A 1$ & $L A 2$ & $A P$ & $M D$ \\
\hline Day & 3.81 & 8.21 & 2.48 & 5.98 & 3.29 & 2.65 & 5.14 \\
\hline Night & 2.77 & 9.31 & 3.20 & 5.17 & 2.43 & 2.02 & 6.49 \\
\hline
\end{tabular}

NJ=New Jersey (Autumn 1981); NC=Greensborough (North Carolina) (May 1982); LA1=Los Angeles, California (Feb 1984); LA2=Los Angeles, California (May 1984); AP=AntiochPittsburg, California (June 1984), MD=Baltimore, Maryland.
After this period, the trap was heated to $220^{\circ} \mathrm{C}$ and its contents transferred into the gas chromatograph by a heated transfer line. Gas chromatography conditions were as described in the previous section. Detection was by mass spectrometry (scan mode). The precision of sampling with SUMMA canisters determined by repeat analysis of standard gas mixtures was $\pm 7 \%$. A comparison between the canister and adsorption tube techniques in the same microenvironment showed excellent agreement.

\section{Calibration}

Calibration was performed with gas standards prepared with a Kin Tek permeation unit (Eco Scientific, Stroud, Gloucestershire). Sorbent tubes were spiked with known concentrations of benzene, toluene, and xylene whereas evacuated SUMMA canisters were filled with the standard gas mixture to atmospheric pressure.

\section{Results and discussion}

MICROENVIRONMENT MONITORING

Table 2 shows the monoaromatic hydrocarbon concentrations in different microenvironments. Increased exposure to volatile organic compounds in the outdoor environment was experienced while refuelling the car with petrol and during driving. This is especially notable in areas where the dispersion is limited-for example, road tunnels and in multistorey car parks. Surprisingly, concentrations in the city centre were modest even though dense traffic surrounded the area. However, for security reasons, the sampling equipment was placed at a height of about $25 \mathrm{~m}$ and at a distance of $20 \mathrm{~m}$ from the roadside, and will hence underestimate ground level exposures. Low hydrocarbon concentrations were also present while travelling on railway trains and in the London Underground. The most prominent source of indoor pollution is tobacco smoke-for example, in smokey public houses. Toluene and xylene concentrations were also significant in indoor areas contaminated with paint fumes (due to their use in paint solvents). Haevner et $a l^{9}$ have suggested that emissions from gas cookers may also be a significant source of benzene and toluene when cooking, although this possibility was not tested explicitly in our study.

Concentrations (ppb) inside the home (both overnight and daytime, but not when cooking) are compared with previously reported data (table 3). In our study, homes were a mixture of flats, detached, semidetached, and terraced houses which had not been recently decorated. 

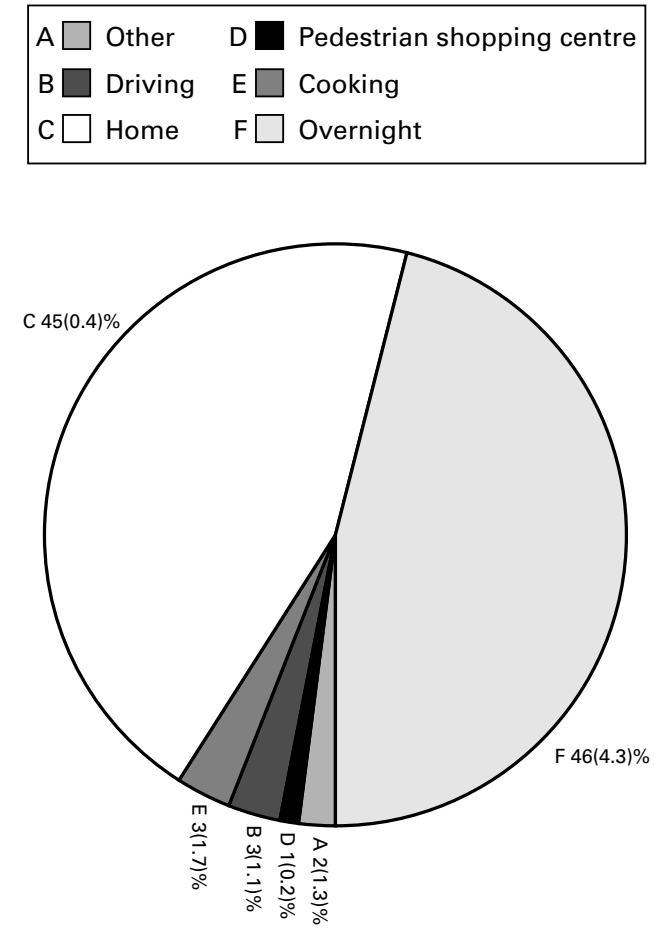

Figure 1 Percentage contribution of different microenvironments to annual average benzene exposure for elderly subjects. Other=sum of the microenvironments bus $(0.44 \%)$, walking $(0.70 \%)$, shopping $(0.37 \%)$, and refuelling $(0.02 \%)$

From table 3 it can be seen that indoor concentrations are broadly similar in all of these studies, although data from The Netherlands show generally lower concentrations than for the other countries.

Personal exposure measurements

The variation of monoaromatic hydrocarbon (MAH) concentrations inside the home throughout the night remained relatively constant and varied from $0.5-2 \mathrm{ppb}$. This indicates a steady contribution from both indoor and outdoor sources. Tables 4 and 5 compare average personal exposures for daytime and night time, showing slightly lower values for night time. This was because daytime measurements were made in several microenvironments (some with increased hydrocarbon concentrationsfor example, driving), whereas night time concentrations were monitored in the bedroom only. Table 4 compares measured personal exposure also with fixed site monitoring data from the automatic urban network (AUN) site in suburban east Birmingham. There is a consistent picture of higher daytime than night time exposures and exposure concentrations exceeding fixed point data, expecially for benzene and toluene. When comparing urban based exposures (table 4) with non-urban, a consistent trend can be seen with higher concentrations obtained from subjects based in Birmingham. This is especially prominent for benzene and toluene, with a daytime increment of $1.71 \mathrm{ppb}$ for benzene amd $1.48 \mathrm{ppb}$ for toluene for urban dwellers.

Daytime exposure levels from this study were comparable with previously published data for benzene (table 6). The exposures of
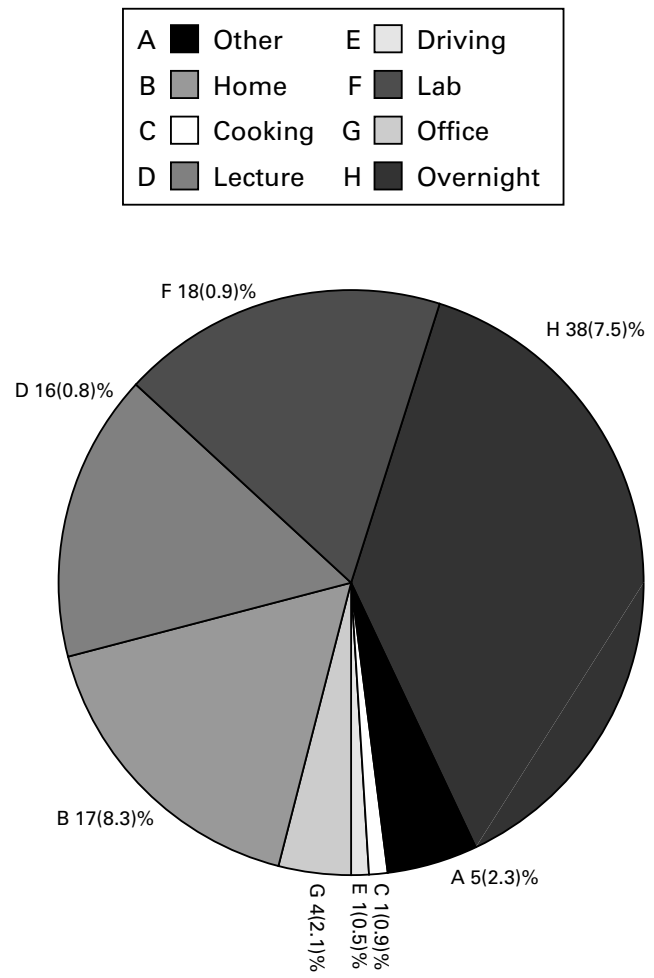

Figure 2 Percentage contribution of different microenvironments to annual average benzene exposure for student subjects. Other=sum of the microenvironments underground $(0.06 \%)$, bus $(0.39 \%)$, train $(0.21 \%)$, shopping $(0.25 \%)$, cycling $(0.67 \%)$, pedestrian shopping centre $(1.87 \%)$, bar $(1.04 \%)$, walking $(0.77 \%)$, and refuelling $(0.01 \%)$.

each volunteer were greatly dependent on the microenvironments occupied. This is illustrated in the two very distinct exposure profiles observed for office workers and for people who spent most of their time at home. For office workers, high exposures were experienced when driving in the morning and afternoon rush hour (approximately $7.8 \mathrm{ppb}$ for benzene), with fairly constant concentrations (approximately $1 \mathrm{ppb}$ for benzene) between these two times (corresponding to office hours). However, for homemakers, exposures were fairly constant throughout the day as the subject was in the house throughout ( 0.2 to 0.4 ppb for benzene).

A considerable range of concentrations was measured in each microenvironment due to variations in emission and in some cases (for outdoor environments) meteorological factors. For example, when driving, high (from congested traffic) and low (from rural and non-rush hour travelling) concentrations were apparent. By contrast, exposures in the home environments were generally lower, with a few high concentrations due to emissions from a variety of indoor sources such as air fresheners, mothballs, furnishings, and clothing.

Season may have an important bearing on exposure as it influences not only meteorology (in winter, outdoor concentrations are higher due to poorer dispersion) but also personal activities (people are more inclined to drive rather than walk in the winter). Unfortunately, each volunteer was not asked to repeat the experiment for each of the four seasons due to 

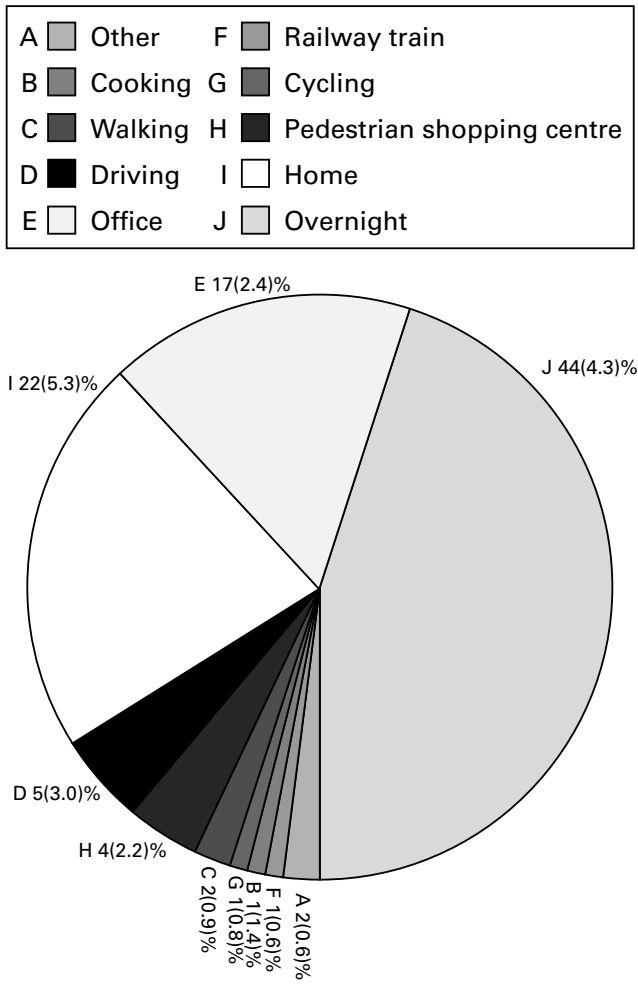

Figure 3 Percentage contribution of different microenvironments to annual average benzene exposure for office worker subjects. Other=sum of the microenvironments underground (0.13\%), shopping (0.29\%), bar (0.61\%), bus $(0.80 \%)$, and refuelling $(0.02 \%)$.

the nature of the sampling programme. However, the variation in personal activities throughout the year was considered by a questionnaire completed by the volunteers.

\section{Percentage contribution of different}

microenvironments to overall annual exposure

To determine the contribution of different microenvironments to overall exposure to MAHs, volunteers were classified into four main categories depending on their age and occupation: elderly people (five volunteers), student (15 volunteers), office worker (15 volunteers), and homemakers ( 15 volunteers). For volunteers in each group, activity diaries (during the 12 hour monitoring period) and questionnaires (based on activities for one year) were analysed to determine the number of hours spent in each environment over a full year. The percentage annual contribution from microenvironment $\mathrm{x}$ to personal exposure was then calculated as follows:

$\%$ age annual exposure to MAH due to $x=$

$\frac{\text { exposure from } \mathrm{x} \text { in one year (ppb.h) }}{\text { total benzene all microenvironments (ppb.h) }} \times 100$

For example, the contribution of driving to annual benzene exposure:

When driving average benzene concentration $=1.94 \mathrm{ppb}$

Number of hours spent driving in one year $=$ 598

Therefore annual exposure to benzene from driving $=1.94 \times 598=1160 \mathrm{ppbh}$

Total benzene exposure from all microenvironments $=24470 \mathrm{ppbh}$
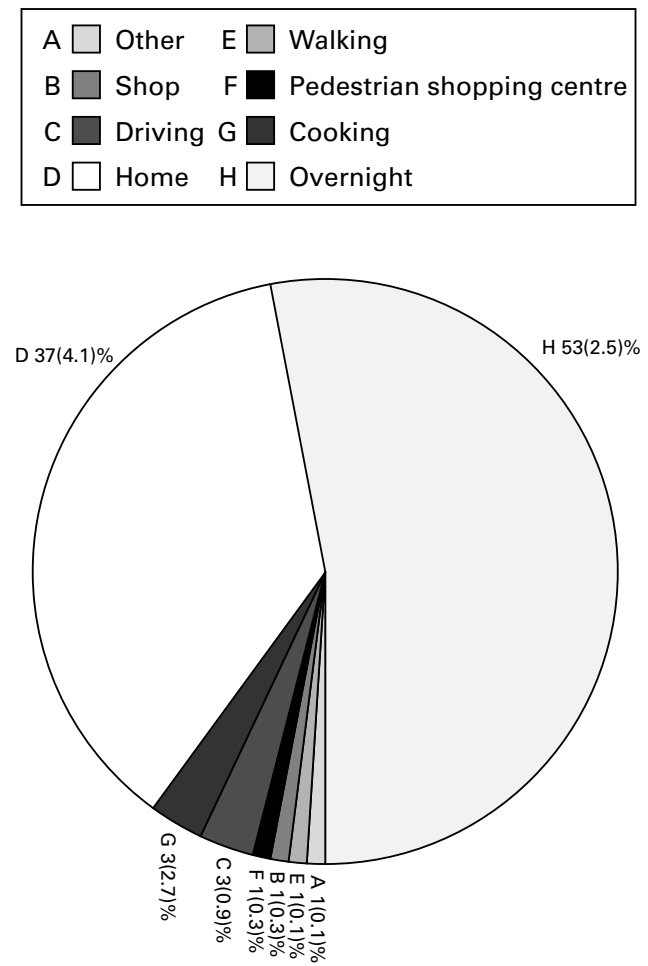

Figure 4 Percentage contribution of different

microenvironments to annual average benzene exposure for homemaker subjects. Other=sum of the microenvironments railway train $(0.24 \%)$, bar $(0.37 \%)$, and refuelling $(0.02 \%)$.

So the percentage contribution of driving to annual benzene exposure $=4.74 \%$.

Note that the annual average benzene exposure during driving takes into account the high exposures obtained from commuting in rush hour times as well as from driving in less congested conditions.

Certain microenvironments featured prominently for each group of volunteers - for example, elderly subjects spent most of their time at home. The percentage contributions of these dominant microenvironments to overall annual exposure for each volunteer type were calculated (fig 1 (elderly people), fig 2 (students), fig 3 (office workers), and fig 4 (homemakers) for benzene only). It must be noted however, that some individual volunteers within each category were not exposed to all the microenvironments shown on their respective graphs due to the averaging which is involved in producing these figures.

When considering the exposure to volatile organic compounds in different microenvironments and the time spent at that environment, the following make a considerable contribution to annual exposure to volatile organic compounds.

- Home environment-Although concentrations within the home were relatively small (compared with activities such as refuelling), a large percentage of time is spent within this microenvironment, especially at night. This was particularly prominent for volunteers in elderly and homemaker categories, who spent much of their time at home. Certain homes had particularly high volatile organic compound concentrations due to increased emissions 


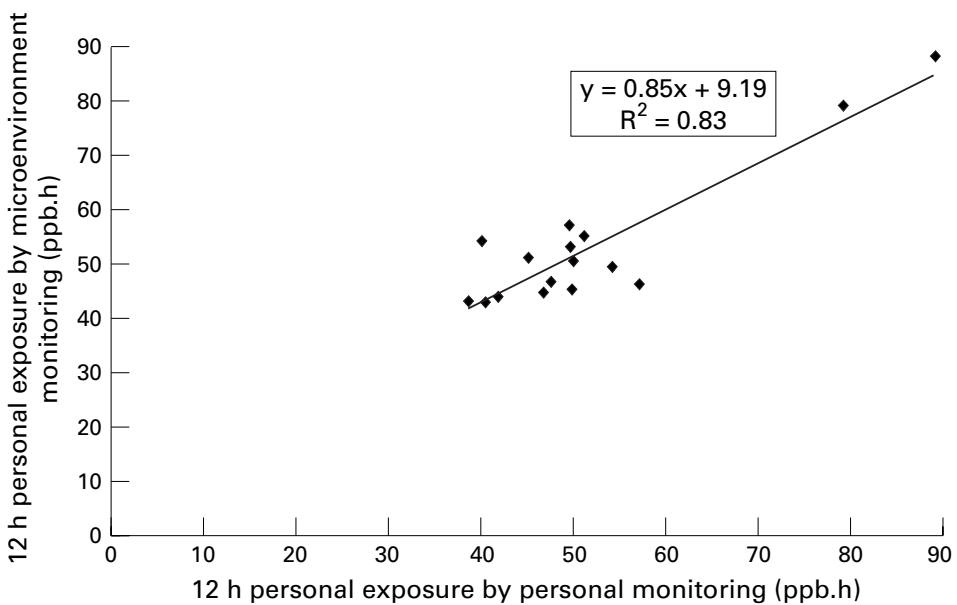

Figure 5 Comparison of $12 \mathrm{~h}$ average personal exposure to benzene from personal monitoring and from microenvironment modelling for Birmingham subjects.

from certain indoor sources-for example, from furnishings. In these cases, the contribution of the home to annual exposures was further increased.

- Laboratory-Student volunteers in this study worked in science laboratories, which use a substantial amount of solvents. Figure 2 shows the percentage of an annual contribution of MAH attributable to occupation only, which would not be applicable for most of the public.

- Office and lecture theatre-Various indoor sources contribute to the annual exposure of volatile compounds. Much of the workforce was exposed to such an environment for long and frequent periods (figs 2 and 3), hence the contribution of this microenvironment to overall annual exposure was substantial.

- Driving-Although less time was spent driving compared with the other environments, higher concentrations were apparent. These were further increased with volunteers who commuted during the morning and afternoon rush hours or travelled in congested traffic. A lower contribution from driving was apparent with volunteers in the elderly and homemaker groups. Analysis of these subjects' activity diaries showed that driving was performed infrequently and during non-rush hour times. The contribution of the activity would feature more

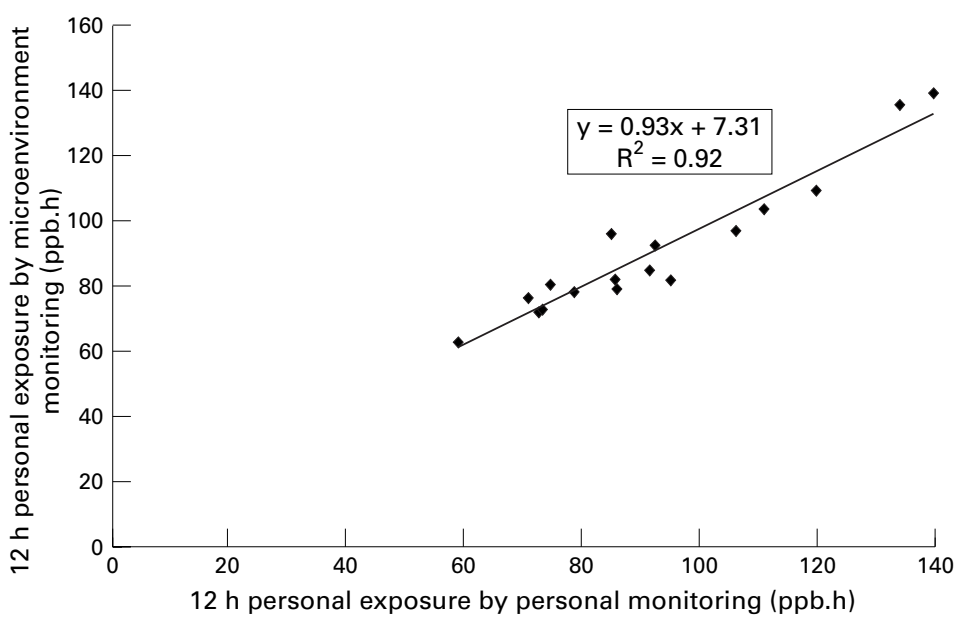

Figure 6 Comparison of $12 \mathrm{~h}$ average personal exposure to toluene from personal monitoring and from microenvironment modelling for Birmingham subjects. prominently with people who spend most of their day driving - for example, delivery drivers.

The following microenvironments gave only a small contribution to annual exposure to volatile organic compounds.

- Walking or cycling - This form of transport was popular among the volunteers in the workforce. Although increased exposures were present, these were not as notable as for drivers (due to the small period spent in traffic and the greater distance from vehicle exhaust).

- Bar-The volunteers who wore personal samplers in a bar environment were not exposed appreciably to tobacco smoke. However, it is likely that at certain times passive smoking could be a prominent factor in such microenvironments (table 1) which would lead to an increased dose of volatile organic compounds. Unfortunately, at these times, personal sampling proved very unpopular among volunteers.

- Refuelling-As expected, although high concentrations were present when refuelling the car, when the frequency and time spent in the environment was considered, this activity gave only a small contribution to overall exposure to volatile organic compounds. However, it was more notable among car commuters due to regular refuelling episodes throughout the year.

Comparison of concentrations from personal monitoring and microenvironment exposure

Personal exposure for each volunteer was evaluated from this study by a series of direct (from the personal monitoring protocol) and indirect (from the microenvironment study) measurements, with the indirect measurements resulting in an estimated (or modelled) personal exposure, calculated by the equation:

$$
\begin{aligned}
& 12 \text { hour integrated } \\
& \text { personal exposure (ppb.h) }
\end{aligned}=\sum_{0}^{x} C_{x} t_{x}
$$

where $\mathrm{C}=$ mean concentration in microenvironment $\mathrm{x}^{x}$ (from microenvironment study); $\mathrm{t}_{x}$ $=$ time spent in microenvironment $\mathrm{x}$.

Figures 5-8 compare the 12 hour integrated personal exposure for each non-smoking subject from personal monitoring and microenvironment experiments for the Birmingham subjects. Personal exposure estimates obtained from the microenvironment study generally correlated well with directly measured personal exposures. Due to low $o$-xylene exposures, the correlation between the two exposure estimates of this compound were relatively poor compared with other compounds $\left(R^{2}=0.67\right)$. However, when performing similar comparisons with volunteers from outside Birmingham, estimated exposures tended to overestimate real exposures as microenvironment measurements were based in urban areas. These concentrations tended to be higher than those within the same environment in more rural areas.

The reasons for differences between directly measured and indirectly estimated personal exposures were evaluated by subtracting concentrations obtained from the personal 


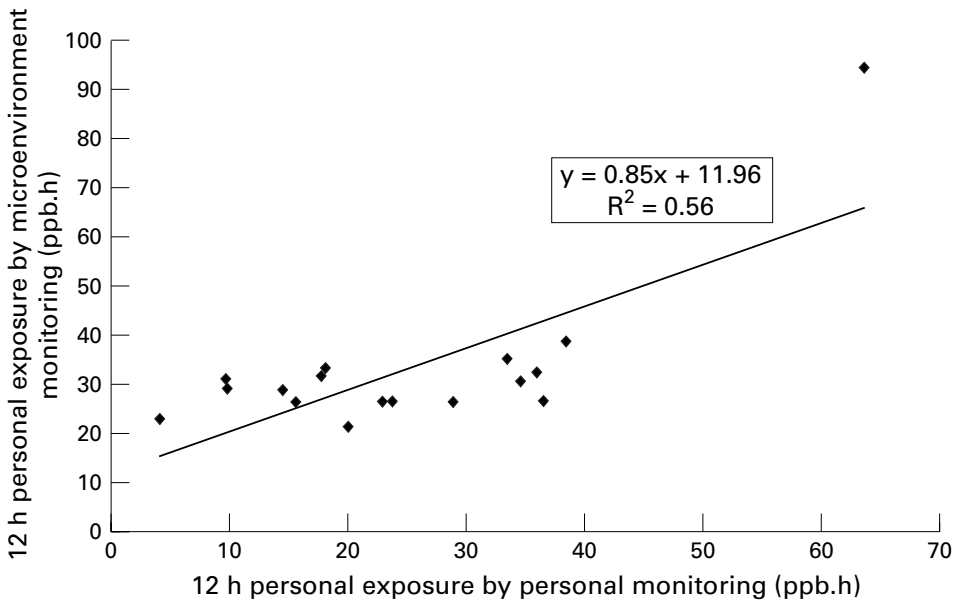

Figure 7 Comparison of $12 \mathrm{~h}$ average personal exposure to p-xylene/m-xylene from personal monitoring and from microenvironment modelling for Birmingham subjects.

monitoring experiment (per microenvironment) with the mean concentration from the independent microenvironment study. This resulted in a series of frequency distribution graphs. A high frequency around zero indicated a close relation between the two studies, hence the monitoring of the microenvironment formed a good basis for personal exposure when in that environment. However, a high frequency in the positive or negative ranges indicated an underestimation or overestimation respectively from microenvironment monitoring for personal exposure. A particularly wide range of differences for toluene was found in all microenvironments. This indicates a wide range of personal exposures to this compound even in the same microenvironment - for example, home-due to varying emissions from various sources-for example, furnishings. A high frequency around zero was obtained for the other compounds and most microenvironments-for example, home and railway train. Therefore, concentrations from the independent microenvironment study give a good indication of the levels of personal exposure.

A wide range of (personal exposure - microenvironment) values were apparent when driving due to people travelling at various times. High frequencies in the positive range (per-

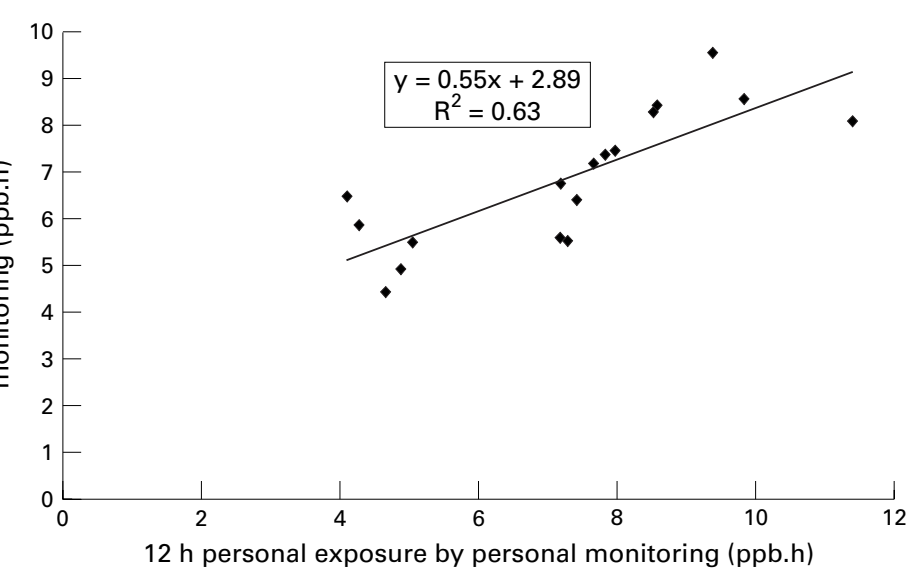

Figure 8 Comparison of $12 \mathrm{~h}$ average personal exposure to o-xylene from personal monitoring and from microenvironment modelling for Birmingham subjects. sonal exposure exceeded microenvironment concentrations) were due to high personal exposures when travelling during the rush hour or just after refuelling. However, high frequencies in the negative range were obtained when driving in rural areas or in non-rush hour times. In these instances, the microenvironment study did not give a good indication of personal exposure due to various driving conditions being present.

Surprisingly, higher frequencies of negative values were present when cycling or walking and personal exposures were compared with roadside microenvironment data. However, most people who used this mode of transport either travelled in non-rush hour periods or in small towns. Smaller frequencies at high positive values were obtained from people travelling in Birmingham rush hours along busy roads.

Differences between direct and indirect personal exposure measurements may also result from the fact that microenvironment monitoring does not take place within the breathing zone, but at various heights and locations.

\section{Cigarette smoking}

Passive smoking can be a major factor influencing personal exposure levels. During the independent microenvironment study, sampling was performed in a bar contaminated with tobacco smoke and high concentrations were measured (table 2). However, volunteers who were in the bar during the personal monitoring study were subjected to little or no tobacco smoke. Nevertheless, it is likely that at certain times, smoking would be a prominent factor in such an environment and this aspect of personal exposure may have been underestimated.

The direct intake of benzene due to active smoking has been specifically excluded from consideration in the study. However, some of the volunteers were smokers and are exposed to greater environmental concentrations of MAHs due to the presence of environmental tobacco smoke. When compared with the daily exposures of non-smokers, mean benzene concentrations were $7.2 \mathrm{ppb}$ and $3.6 \mathrm{ppb}$ for smokers and non-smokers respectively. However, in the situation where smoking occurred every hour throughout the sampling period, 12 hour daily exposures were increased further (to a maximum value of $17.8 \mathrm{ppb}$ ). As the microenvironment study measured MAH concentrations with no environmental tobacco smoke (apart from in the smoky bar), estimated personal exposures derived from these concentrations were highly inaccurate compared with actual exposures from volunteers who smoked.

\section{Conclusion}

High hydrocarbon concentrations were present in several environments, consistent with other research on this topic. Thus, exposures when driving, ${ }^{13}$ painting,${ }^{14}$ smoking, ${ }^{6}$ and car refuelling were increased. However, when the time spent in each environment was considered, the annual contribution of certain high concentration environments to personal exposure was 
found to be small. As most of the public spend much of their time indoors, homes and offices featured prominently in overall exposure. Smoking was also a notable factor, increasing benzene concentrations by up to $3.6 \mathrm{ppb}$ compared with non-smokers. Concentrations in the home in this study were comparable with other published data from other countries and daytime exposures were also similar. In general, personal exposures to all of the measured hydrocarbons were significantly higher than those measured over the period of the study at a background monitoring station in the same city. This was also reported in a similar study which measured indoor home concentrations of up to 1.6 times greater than those measured outdoors. ${ }^{12}$ Clearly background outdoor air provides only a baseline of exposure on which the contributions of other sources are superimposed.

Comparison of the exposure estimates derived from the microenvironment or activity diary study with direct measurements of personal exposure shows a good agreement between the two methods. Clearly for some people, particularly smokers, this approach will not lead to accurate estimates as it is based on mean microenvironment concentrations, but for obtaining estimates of typical exposures for particular activity patterns or population groups, the approach seems to work well.

There are several limitations in this study due to the nature of the monitoring. Due to the non-payment of volunteers, personal exposure monitoring was based on volunteers who were well known to the authors of this paper. Therefore, the results may be subject to slight bias as the population sampled was not randomly selected. Hence, results cannot be directly extrapolated to the general public. Further to this, the number of elderly subjects, homemakers, students, and office workers were not evenly distributed among urban and nonurban areas - for example, all students were based in Birmingham, whereas all elderly subjects resided in non-urban areas. Also, this study heavily relied upon the generous nature of the volunteers, hence in some instances (night time monitoring) the number of observations tended to be low. There are also several potential sources of systematic bias in this study, especially with regard to the evaluation of the influence of passive smoking on personal exposure. Passive smoking was considered only through monitoring inside bars during busy periods and volunteers were unwilling to wear personal samplers when in the bar. However, other settings-for example, offices-which might be subject to contamination by environmental tobacco smoke were not considered as owners of such areas were not enthusiastic over the idea of personal monitoring.

We are grateful for the assistance of the volunteers who participated in this study.

1 Department of Environment, Expert Panel on Air Quality Standards. Benzene. London: HMSO, 1994.

2 World Health Organisation. Draft revisions to air quality guidelines. Copenhagen: WHO, December 1996, in press.

3 Quality of Urban Air Review Group (QUARG). First report: urban air quality in the United Kingdom. London: Department of the Environment, January 1993.

4 AEA Technology. Air pollution in the UK. 1995. Culham: AEA Technology, 1996.

5 Wallace LA. Major sources of benzene exposure. Environ Wealth Perspect 1989;82:165-9.

6 Gee IL, Perry R. Vehicle emissions and effect on air quality: Gee IL, Perry R. Vehicle emissions and effect on air quality:
indoor and outdoors. Indoor Environment 1994;3:224-36. indoor and

8 Riveros-Rosas H, Pfeifer GD, Lyman DR, et al. Personal exposure to elements in Mexico City air. Sci Total Environ 1997;198:79-96.

9 Haevner DL, Morgan WT, Ogden MW. Determination of volatile organic compounds and ETS apportionment in 49 homes. Environment International 1995;21:3-21.

10 Krause C, Mailahn W, Nagel R, et al. Occurence of volatile organic compounds in the air of 500 homes in the Federal Republic of Germany. In: Indoor air 1987. Proceedings of the 4th International Conference on Indoor Air Quality and Climate. West Berlin:
Hygiene, 1987:102-6.

11 Lebret E, Van de Weil HJ, Noij D, et al. Volatile hydrocarbons in Dutch homes. Environment International hydrocarbons in

12 Berry RW, Brown VM, Coward SKD, et al. Indoor air quality in homes: part 1, the Building Research Establishment indoor environment study. Watford: Building Research Establishment, 1996. (Building Research Establishment Report, CI/SfB 81 (H6) (L2).)

13 Löfgren L, Persson K, Strömvall AM. Exposure of commuters to volatile aromatic hydrocarbons from petrol exhausts. Sci Total Environ 1991;108:225-33.

14 Namiesnik J, Gorecki T, Kozdron-Zabiegala B, et al. Indoor air quality (IAQ), pollutants, their sources and concentration levels. Buildings and Environment 1992;27:339-56. 